\title{
Determinants of low birth weight among newborns delivered at Tirunesh Beijing General Hospital, Addis Ababa, Ethiopia: a case- control study
}

\author{
Mesfin Tadese ${ }^{1 *}$, Abdulwahhab Seid Minhaji ${ }^{2}$, Chalachew Tegegne Mengist ${ }^{2}$, Fetene Kasahun ${ }^{1}$ and \\ Getaneh Baye Mulu²
}

\begin{abstract}
Background: Low birth weight is weight less than $2500 \mathrm{~g}$ or $5.5 \mathrm{lb}$. at birth. Globally, more than 20 million infants (1520\%) are born with a low birth weight each year. Birth weight is the primary indicator of the health status of neonates and is the primary factor that determines the infant's physical, survival, and mental growth. Thus, the study aimed to investigate the determinants of low birth weight among newborn babies delivered at Tirunesh Beijing General Hospital, Addis Ababa, Ethiopia.
\end{abstract}

Methods: We performed a facility-based unmatched case-control study among 453 (151 cases and 302 controls) deliveries conducted at Tirunesh Beijing General Hospital. Birth records and maternal antenatal care (ANC) files were reviewed from March 1 to April 30, 2019. Consecutive sampling was employed to select study participants. Data were entered into Epi-data version 4.2.1 and analyzed using SPSS version 25 statistical software. Descriptive statistics and logistic regression analysis were computed to identify independent determinants of low birth weight. A p-value of $\leq 0.05$ was used to declare statistical significance.

Result: Four hundred fifty-three birth records of babies (151 cases and 302 controls) were reviewed. Women who reside in rural area $[A O R(C I)=3.12(1.63-5.98)]$, being merchant $[(A O R(C I)=2.90(1.03-8.22)]$, danger sign during pregnancy $[(A O R(C l)=4.14(1.68-10.2)]$, and maternal weight during pregnancy $[(A O R(C l)=4.94(3.26-7.52)]$ were found to be a significant determinants of low birth weight.

Conclusion: Residence, occupation, danger signs, and maternal weight during pregnancy were significant determinants of low birth weight. Socioeconomic development, early detection and management of complications, and encouraging nutrition and weight during pregnancy are crucial for minimizing the risk of delivering low birth weight babies.

Keywords: Low birth weight, Determinants, Case-control, Ethiopia

\footnotetext{
*Correspondence: mesitad031@gmail.com

1 Department of Midwifery, College of Health Sciences, Debre Berhan University, Debre Berhan, Ethiopia

Full list of author information is available at the end of the article
}

\section{Background}

The birth weight of a newborn baby is the first weight record, preferably taken within an hour of birth. Birth weight is a good summary of multifaceted public health problems, including long-term maternal malnutrition, chronic illness, and poor health care during pregnancy 
[1]. World Health Organization (WHO) defines low birth weight (LBW) as the weight of a newborn baby below $2500 \mathrm{~g}$ at birth regardless of the gestational age. Further classification of low birth weight includes; low birth weight (below $2500 \mathrm{~g}$ ), very low birth weight (below $1500 \mathrm{~g}$ ), and extremely low birth weight (below $1000 \mathrm{~g})$ [2].

Every year more than 20 million babies are born weighing below $2500 \mathrm{~g}$. Globally, this figure accounts for $17 \%$ of total birth in low-income countries, a rate more than twofold that of developed countries (7\%) [2]. For example, the prevalence of low birth weight in Ghana, Burkina Faso, Senegal, Malawi, and Uganda was $10.2,13.4,15.7,12.1$, and $10 \%$, respectively [3]. In Sub-Saharan Africa, the burden of low birth weight was 9.6\% [4]. A cross-sectional study in Ethiopia revealed a $12.5 \%$ prevalence of low birth weight in Butajira [5] and $15.8 \%$ in Wolaita Sodo [6].

Low birth weight babies are highly vulnerable to death during their early childhood periods. Even those who escaped death in their early months and years are still prone to a high incidence of chronic diseases like type II diabetes mellitus, cardiovascular disease, hypertension, immunodeficiency, and impaired language development in their adulthood and old age. It also hurts their reproductive outcomes, i.e., preterm and low birth weight, and neurocognitive development such as intellectual disability, learning impairment, cerebral palsy, retinopathy, and mental retardation [7].

A baby's birth weight is substantially influenced by the mother's early life, including fetal growth, childhood and adolescent nutrition, hereditary, and body composition during conception [7]. Other predictors of LBW include socioeconomic status, parity, mid-upperarm-circumference, insufficient gestational weight gain, lack of antenatal care (ANC) follow-up, preterm labor, medical and obstetric complications, physical activity, smoking, and bad obstetric history [3, 8, 9].

According to the Ethiopian Demographic Health Survey, the burden of low birth weight in Ethiopia was not decreased significantly, 11\% in 2011 and 13\% in 2016 [1, 10]. This might be attributed to insufficient improvements in the quality of health care services, including delivery at health facilities, ANC coverage, postnatal services, and vaccination [11]. Maintaining good nutrition and healthy weight gain, especially at the beginning of conception, controlling pre-existing medical and obstetric illnesses, increasing intake of folic acid found in fruits, whole grains, and vegetables, good preconceptional care and ANC follow-ups, and improving the living standards of the general population were the tips to lower the risks of low birth weight [12].
In Ethiopia, LBW is still a significant public health concern. The attainment of a sustainable development goal is also intensely affected by the progress in newborn deaths. The government of Ethiopia has appreciated the depth of the problem, and nowadays, some changes are being employed by governmental, non-governmental organizations (Columbia University International Center for AIDS Care and Treatment Program (CU-ICAP), WHO), and professional associations like Ethiopian pediatrics society. Evidence-based intervention is required to reduce the burden of the problem and improve newborns' survival. Observational data on the incidence and determinants of low birth weight are essential for designing interventional activities, particularly in Sub-Saharan Africa [13]. Thus, the study aimed to assess the determinants of low birth weight among newborn babies delivered at Tirunesh Beijing General Hospital, Addis Ababa, Ethiopia.

\section{Methods}

\section{Study area, period, and design}

A facility-based unmatched case-control study was conducted in Tirunesh Beijing General Hospital, Addis Ababa, from March 1 to April 30, 2019. The hospital is found South of Addis Ababa, the capital city of Ethiopia. The town contains ten sub-cities and 116 woredas. It has 12 governmental and nine non-governmental hospitals. Tirunesh Beijing General Hospital is one of the famous public general hospitals providing a range of medical, maternal, and child health services, including delivery services and various inpatient and outpatient healthcare services for more than four hundred thousand catchment populations surrounding the Oromia region.

\section{Population}

In the preceding year, all mothers delivered in Tirunesh Beijing General Hospital were the source population. There were 3798 deliveries in the past year. Cases were those newborns with low birth weight (LBW) (weight of $<2500 \mathrm{~g}$ ) and controls (Normal Birth Weight) were those live births weighing $\geq 2500 \mathrm{~g}$ and those delivered on the same day as enrolled regardless of the mode of delivery. All singleton births delivered after 28 weeks of gestation or weight of at least $1000 \mathrm{~g}$, and with available information on birth weight in the medical records were included. Newborns with twin or multiple births, visible congenital deformity, i.e., hydrocephalus, stillbirths, birth weight $\geq 4000 \mathrm{~g}$, and incomplete data were excluded from the study.

\section{Sample size determination}

The sample size was determined using the Open Epi version 3.03 statistical software package. The 
following considerations were made: percent of controls exposed, odds ratio, confidence level $95 \%$, power $80 \%$, and the ratio of controls to cases 2 (Table 1). By adding $5 \%$ for incomplete or missed data, the largest sample size becomes 482 (161 cases and 321 controls).

\section{Variables of the study}

Birth weight was the outcome variable. Socio-demographic factors (i.e., maternal age, educational level, occupation, marital status, and residence), maternal and obstetrics characteristics (i.e., weight during pregnancy, gravidity, parity, history of abortion, gestational age at birth, and ANC follow up), and complications during pregnancy, (i.e., chronic hypertension, pregnancy-induced hypertension, and danger sign of pregnancy) were the exposure variables.

\section{Measurements \\ Birth weight}

The weight of the newborns measured within the first 15 min of birth [15].

\section{Normal birth weight}

Weight at birth between $2500 \mathrm{~g}$ and $4000 \mathrm{~g}$.

\section{Danger signs of pregnancy}

Any one or more early or late pregnancy bleeding, leakage of amniotic fluid, reduced fetal movement, severe headache, convulsion, blurred vision, fever, and severe abdominal pain [14].

\section{Gravidity}

The number of times a woman has been pregnant, whether a term, live births, stillbirth, abortion, ectopic, or molar pregnancy.
Parity

The number of times a woman gives birth to a fetus with a gestational age of 28 weeks or more, regardless of the outcome.

\section{Iron and folic acid supplementation}

For this study, mothers who supplemented and took iron and folic acid for at least 3 months were considered as "Yes."

\section{Merchant}

Women trades in commodities produced by other people, i.e., vegetables (onion, tomatoes, cabbage, potato), plastics (bucket, seat), clothing (trousers, underwear, shoes, t-shirt,) metals (metallic pot, teapot).

\section{Maternal weight}

The data were derived from four weight measurements in pregnancy from antenatal care registration books, and the average weight was considered for analysis.

\section{Data collection tools and procedure}

A structured and pre-tested checklist was used to extract the maternal antenatal care (ANC) files and birth records. The checklist was designed from the Demographic Health Survey questionnaire and other similar literature works $[9,14,18]$. The checklist consists of socio-demographic, maternal, and neonatal factors. Socio-demographic characteristics, maternal and obstetrical variables were extracted from birth records, while pregnancy complications were obtained from the ANC records. Newborn features, including birth weight and gender, were extracted from the birth records. At birth, the gestational age was calculated using the last normal menstrual period (LNMP) and a review of the maternal history for early ultrasound examination and urine test.

Four trained midwives and one supervisor participated in the data extraction. Consecutive sampling was

Table 1 Sample size calculation for determinants of low-birth-weight among women delivered at Tirunesh Beijing General Hospital, Addis Ababa, Ethiopia

\begin{tabular}{|c|c|c|c|c|}
\hline Variables & $\begin{array}{l}\text { Percent of controls } \\
\text { exposed }\end{array}$ & Adjusted odds ratio & $\begin{array}{l}\text { Sample size Cases/controls } \\
\text { [Total] }\end{array}$ & References \\
\hline Gestational age & 55.8 & 5.32 & $31 / 63[94]$ & {$[14]$} \\
\hline Chronic diabetes & 85.7 & 0.27 & $29 / 59[88]$ & \\
\hline Signs of pregnancy complication & 48.3 & 2.7 & $61 / 122[183]$ & \\
\hline Sex of newborn & 13.5 & 2.1 & $161 / 321[482]$ & {$[15]$} \\
\hline Maternal age & 51.2 & 3.1 & $50 / 101[151]$ & {$[16]$} \\
\hline Residence & 51.9 & 2.1 & $106 / 211[317]$ & \\
\hline Maternal education & 3.9 & 6.0 & $57 / 113[170]$ & \\
\hline Folate supplementation & 29 & 5.48 & $22 / 44[66]$ & [17] \\
\hline
\end{tabular}


employed to select cases and controls. For each case (low birth weight) record, two consecutive controls (normal birth weight) records were set and reviewed starting from the data collection date.

\section{Data quality control}

The questionnaire was first prepared in English and later translated to the local language, Amharic, and then back to English by an independent translator to keep the data collection instrument consistent. The tool was first pretested on $5 \%$ of the samples (8 cases and 15 controls) in Zewditu Memorial Hospital before the actual date of data collection. A necessary adjustment was considered following the result of the pre-test. A one-day training has been given concerning the objective, instrument, and data collection procedure for both data collectors and supervisors. The supervisor and the principal investigators checked and reviewed the collected data for clarity, completeness, and accuracy.

\section{Data management and analysis}

The data were coded, cleaned, and edited. Errors identified during the data cleaning were adjusted after reviewing the original data using the code numbers. Data were entered into Epi-Data version 4.2.1 and analyzed using SPSS version 25 statistical software. The descriptive statistics were summarized and presented using frequency tables, means, standard deviation, and percentages. When the frequencies became smaller, re-categorization/recoding of variables was done. Variables with a $p$-value of $\leq 0.25$ in the bivariable logistic regression were selected for the final model. Multivariable logistic regression models were run to identify independent determinants of LBW. The level of multi-collinearity was checked and fitted using variance inflation factor and tolerance. An adjusted odds ratio (AOR) with a 95\% confidence interval $(\mathrm{CI})$ was reported to describe the strength of association. The Omnibus test and Hosmer-Lemeshow goodness-of-fit were applied to check for model fitness. A statistically significant level was stated at a $p$-value of $<0.05$.

\section{Result}

\section{Baseline characteristics}

A total of 453 (151 cases and 302 controls) birth records and antenatal care files were reviewed. The mean $( \pm$ SD) age of cases and controls were $29.17 \pm 7.12$ and $27.22 \pm 5.59$, respectively. Twenty-nine (6\%) records were incomplete and excluded from the analysis. About 58.3\% of cases and $77.5 \%$ of controls were within $20-35$ years. Eighty-six (57\%) cases reside in rural areas, while two hundred ten $(69.5 \%)$ of controls were urban residents. Around $33.1 \%$ of cases and $27.5 \%$ of controls had attended primary school, and $40.6 \%$ of the case group and $21.2 \%$ of the control group mothers were within the weight range of $50-60 \mathrm{~kg}$ during their recent pregnancy. Further, nearly half of mothers in cases $(49.7 \%)$ and controls $(50.7 \%)$ were housewives (Table 2).

\section{Obstetrics, antenatal, and newborn characteristics}

The mean $( \pm \mathrm{SD})$ birth weight was $2133.5 \pm 332.88 \mathrm{~g}$ for the low-birth-weight newborns and $3080 \pm 360.93 \mathrm{~g}$ for the normal birth weight newborns. About $66.3 \%$ of cases and $55 \%$ of controls were multiparas, and $83.4 \%$ of cases and $89.4 \%$ of controls were supplemented with iron during pregnancy. The majority of the case group (86.1\%) and control group mothers (91.4\%) had antenatal care (ANC) follow-up. Female newborns accounted for the more significant proportion of cases (55.0\%) and controls (51.7\%). Regarding complications during pregnancy, $5.3,19.9$, and $31.8 \%$ of case group mothers had chronic hypertension, pregnancy-induced hypertension, and danger signs of pregnancy, respectively. Additionally, five (3.3\%) of mothers with cases had a history of low birth weight, and twelve $(7.9 \%)$ of mothers had a history of abortion (Table 3).

\section{Determinants of low birth weight}

Bivariable logistic regression analysis was computed, and variables with a $p$-value of $\leq 0.25$ were selected for the multivariable logistic regression analysis model. In the multivariable logistic regression analysis, residence, occupation, danger signs, and maternal weight during pregnancy have shown a statistically significant association with low birth weight (Table 4).

The odds of low birth weight among rural residence were three times higher than the urban counterparts $(\mathrm{AOR}(\mathrm{CI})=3.12$ (1.63-5.98). The risk of low birth weight was also significantly higher among merchant mothers compared to those employed (AOR (CI) $=2.90$ (1.038.22). Furthermore, mothers who had a danger sign during pregnancy were four times more likely to deliver low birth weight babies compared to those who have no danger signs (AOR $(\mathrm{CI})=4.14$ (1.68-10.2). Mothers whose pregnancy weight ranges from 50 to $60 \mathrm{~kg}$ were approximately five times more likely to have low birth weight neonates, compared to those whose weight exceeds $81 \mathrm{~kg}$ $(\mathrm{AOR}(\mathrm{CI})=4.94(3.26-7.52)$.

\section{Discussion}

Low birth weight continues to be a significant cause of neonatal morbidity and mortality. In this study, residence, occupation, danger signs, and maternal weight during pregnancy were significant associates of low birth weight. 
Table 2 Baseline characteristics of women delivered at Tirunesh Beijing General Hospital, Addis Ababa, Ethiopia

\begin{tabular}{|c|c|c|c|c|}
\hline \multirow[t]{2}{*}{ Variables } & \multirow[t]{2}{*}{ Category } & \multicolumn{2}{|c|}{ Birth Weight, $n(\%)$} & \multirow[t]{2}{*}{$P$-value } \\
\hline & & Cases (151) & Controls (302) & \\
\hline \multirow[t]{3}{*}{ Age of the mother } & $<20$ years & $17(11.2)$ & $31(10.3)$ & \multirow[t]{3}{*}{$0.000^{\circledR}$} \\
\hline & 20-34years & $88(58.3)$ & $234(77.5)$ & \\
\hline & $\geq 35$ years & $46(30.5)$ & $37(12.2)$ & \\
\hline \multirow[t]{2}{*}{ Residence } & Urban & $65(43.0)$ & $210(69.5)$ & \multirow[t]{2}{*}{$0.000^{\circledR}$} \\
\hline & Rural & $86(57.0)$ & $92(30.5)$ & \\
\hline \multirow[t]{4}{*}{ Religion } & Muslim & $27(17.9)$ & $65(21.5)$ & \multirow[t]{4}{*}{$0.702^{*}$} \\
\hline & Orthodox & $90(59.6)$ & $166(55.0)$ & \\
\hline & Protestant & $31(20.5)$ & $62(20.5)$ & \\
\hline & Others $^{\mathrm{a}}$ & $3(2.0)$ & $9(3.0)$ & \\
\hline \multirow[t]{4}{*}{ Educational status } & No formal education & $49(32.5)$ & $68(22.5)$ & \multirow[t]{4}{*}{$0.016^{\circledR}$} \\
\hline & Primary & $50(33.1)$ & $83(27.5)$ & \\
\hline & Secondary & $28(18.5)$ & $80(26.5)$ & \\
\hline & Higher education & $24(15.9)$ & $71(23.5)$ & \\
\hline \multirow[t]{4}{*}{ Occupation } & Employed & $26(17.2)$ & $93(30.8)$ & \multirow[t]{4}{*}{$0.001^{\circledR}$} \\
\hline & Merchant & $38(25.2)$ & $42(13.9)$ & \\
\hline & Housewife & 75(49.7) & $153(50.7)$ & \\
\hline & Others $^{b}$ & $12(7.9)$ & $14(4.6)$ & \\
\hline \multirow[t]{4}{*}{ Ethnicity } & Amhara & $61(40.4)$ & $113(37.4)$ & \multirow[t]{4}{*}{$0.168^{*}$} \\
\hline & Oromo & $80(53.0)$ & $157(52.0)$ & \\
\hline & Tigre & $9(6.0)$ & $18(6.0)$ & \\
\hline & Others $^{c}$ & $1(0.7)$ & $14(4.6)$ & \\
\hline \multirow{4}{*}{$\begin{array}{l}\text { Maternal weight during preg- } \\
\text { nancy }\end{array}$} & $50-60 \mathrm{~kg}$ & $61(40.6)$ & $64(21.2)$ & \multirow[t]{4}{*}{$0.000^{\circledR}$} \\
\hline & $61-70 \mathrm{~kg}$ & $58(38.7)$ & $105(34.8)$ & \\
\hline & $71-80 \mathrm{~kg}$ & $25(16.7)$ & $101(33.4)$ & \\
\hline & $\geq 81 \mathrm{~kg}$ & $6(4.0)$ & $32(10.6)$ & \\
\hline
\end{tabular}

${ }^{a}$ Catholic, Seventh-day Adventist

${ }^{\mathrm{b}}$ Daily laborer, waiter, tailor

'Silte, Gurage, Afar

${ }^{\circledR}$ Pearson chi-square

*Fisher's exact test

The odds of low birth weight were higher among mothers from rural residents than their urban counterparts. This finding was consistent with past studies conducted in India [19], Malaysia [8], Dilla town [17], and Bale Zone Hospitals [15]. This could be due to the difference in education, income, and workload. Women from rural areas had significantly lower levels of education. The higher level of education among urban women provides higher household incomes through securing occupations in a professional field and administrative roles. The rural women were actively involved in domestic and outside activities, and they bear double, particularly in Sub-Saharan Africa, including Ethiopia [8]. These low socioeconomic statuses of rural women restrict access to information and health services, antenatal care follow-ups, danger signs of pregnancy, nutritional status, and fetal growth, thus increasing the risk of low birth weight [20].

However, this finding was in contrast with the report from Jimma Zone, Southwest Ethiopia, where the risk of low birth weight was significantly higher among urban residents [21]. This may account for the variations in study design, data collection technique, and study population. For example, in this study, rural women accounted for more significant cases (57\%). But in the latter survey, urban women accounted for more cases (32.6\%) than rural (17.1\%). In addition, urban dwellers were more likely to experience high-risk lifestyles and behaviors, i.e., smoking, khat chewing, and alcohol drinking, that might have resulted in low birth weight.

This study revealed that the risk of low birth weight was significantly higher among merchant mothers. Our finding is concordant with Snijder et al.s finding, which 
Table 3 Obstetrics, antenatal, and newborn characteristics of mothers delivered at Tirunesh Beijing General Hospital, Addis Ababa, Ethiopia

\begin{tabular}{|c|c|c|c|c|}
\hline \multirow[t]{2}{*}{ Variables } & \multirow[t]{2}{*}{ Category } & \multicolumn{2}{|c|}{ Birth Weight, n (\%) } & \multirow[t]{2}{*}{$P$-value } \\
\hline & & Cases (151) & Controls (302) & \\
\hline \multirow[t]{2}{*}{ Gravidity } & Primigravida & $64(42.4)$ & $115(38.1)$ & $0.377^{\circledR}$ \\
\hline & Multigravida & $87(57.6)$ & $187(61.9)$ & \\
\hline \multirow[t]{3}{*}{ Parity } & Primipara & $21(20.2)$ & $72(38.1)$ & $0.203^{\circledR}$ \\
\hline & Multipara & $69(66.3)$ & $104(55.0)$ & \\
\hline & Grand multipara & $14(13.5)$ & $13(6.9)$ & \\
\hline \multirow[t]{2}{*}{ ANC visit } & Yes & $130(86.1)$ & $276(91.4)$ & $0.081^{\circledR}$ \\
\hline & No & $21(13.9)$ & $26(8.6)$ & \\
\hline \multirow[t]{2}{*}{ Iron and folic supplementation } & Yes & $126(83.4)$ & $269(89.4)$ & $0.073^{\circledR}$ \\
\hline & No & $25(16.6)$ & $32(10.6)$ & \\
\hline \multirow[t]{2}{*}{ Hemoglobin } & $<11 \mathrm{~g} / \mathrm{dl}$ & $6(4.0)$ & $5(1.7)$ & $0.192^{*}$ \\
\hline & $\geq 11 \mathrm{~g} / \mathrm{dl}$ & $145(96.0)$ & $297(98.3)$ & \\
\hline \multirow[t]{2}{*}{ Chronic hypertension } & Yes & $8(5.3)$ & $3(1.0)$ & $0.008^{*}$ \\
\hline & No & $143(94.7)$ & $299(99.0)$ & \\
\hline \multirow[t]{2}{*}{ Pregnancy-induced hypertension } & Yes & $30(19.9)$ & $11(3.6)$ & $0.000^{\circledR}$ \\
\hline & No & $121(80.1)$ & $291(96.4)$ & \\
\hline \multirow[t]{2}{*}{ Danger signs during pregnancy } & Yes & $48(31.8)$ & $34(11.3)$ & $0.000^{\circledR}$ \\
\hline & No & $103(68.2)$ & $268(88.7)$ & \\
\hline \multirow[t]{2}{*}{ History of LBW } & Yes & $5(3.3)$ & $3(1.0)$ & $0.124^{*}$ \\
\hline & No & $146(96.7)$ & $299(99.0)$ & \\
\hline \multirow[t]{2}{*}{ History of abortion } & Yes & $12(7.9)$ & $25(8.3)$ & $0.903^{\circledR}$ \\
\hline & No & $139(92.1)$ & $277(91.7)$ & \\
\hline \multirow[t]{3}{*}{ Gestational age } & $<37$ weeks & $105(69.5)$ & $10(3.3)$ & $0.000^{*}$ \\
\hline & 37-42 weeks & $43(28.5)$ & $284(94.0)$ & \\
\hline & $>42$ weeks & $3(2.0)$ & $8(2.7)$ & \\
\hline \multirow[t]{2}{*}{ Sex of the newborn } & Male & $68(45.0)$ & $146(48.3)$ & $0.550^{\circledR}$ \\
\hline & Female & $83(55.0)$ & $156(51.7)$ & \\
\hline \multirow[t]{2}{*}{ Birth defect } & Yes & $6(4.0)$ & $4(1.3)$ & $0.091^{*}$ \\
\hline & No & $145(96.0)$ & $298(98.7)$ & \\
\hline
\end{tabular}

${ }^{\circledR}$ Pearson chi-square

*Fisher's exact test

documented a significant association between being a merchant and low birth weight [22]. This could result from work-related stress and involvement in strenuous activities or heavy physical work. Additionally, they spend most of their time in business or wholesale trade and may not have enough time to care for themselves. Further, such activities might require prolonged standing. In turn, this increases the action of the sympathetic nervous system in the active muscles and results in backflow of blood from visceral arteries to the active muscles, which results in increased sweating, reduced plasma volume, decreased blood perfusion to uterine and placental arteries, thereby reducing the oxygen and nutrients supply to the fetus [22].
Danger signs during pregnancy were also significantly increased the odds of low birth weight. According to this study, mothers who had a danger sign during pregnancy were four times more likely to deliver low birth weight babies. This finding was supported by previous studies done in India [19], Debre Berhan [14], Amhara regional state referral hospitals [23], and Bale zone [15]. The danger signs and symptoms of pregnancy indicate some kind of complication that adversely affects the growth of the fetus. For instance, hypertensive disorders of pregnancy may cause pre-eclampsia, resulting in reduced perfusion and nutrient and oxygen supply to the fetus, resulting in low birth weight or fetal death [23]. Thus, it is recommended that pregnant women be aware of this sign and 
Table 4 Determinants of LBW in Tirunesh Beijing General Hospital, Addis Ababa, Ethiopia

\begin{tabular}{|c|c|c|c|c|}
\hline Variables & Category & COR $(95 \% \mathrm{Cl})$ & AOR $(95 \% \mathrm{Cl})$ & $P$-value \\
\hline \multirow[t]{3}{*}{ Age of the mother } & $<20$ years & 1 & 1 & \\
\hline & 20-35 years & $0.69(0.36-1.30)$ & $0.41(0.07-2.53)$ & 0.337 \\
\hline & $\geq 36$ years & $2.27(1.09-4.72)$ & $2.45(0.38-15.8)$ & 0.348 \\
\hline \multirow[t]{2}{*}{ Residence } & Urban & 1 & 1 & \\
\hline & Rural & $3.02(2.02-4.53)$ & $3.12(1.63-5.98)$ & 0.001 \\
\hline \multirow[t]{4}{*}{ Educational status } & No formal education & $2.13(1.18-3.85)$ & $0.88(0.32-2.43)$ & 0.802 \\
\hline & Primary & $1.78(0.99-3.19)$ & $0.59(0.21-1.69)$ & 0.330 \\
\hline & Secondary & $1.04(0.55-1.95)$ & $0.68(0.25-1.85)$ & 0.448 \\
\hline & Higher education & 1 & 1 & \\
\hline \multirow[t]{4}{*}{ Occupation } & Employed & 1 & 1 & \\
\hline & Merchant & $3.24(1.75-6.00)$ & $2.90(1.03-8.22)$ & 0.045 \\
\hline & House wife & $1.75(1.05-2.94)$ & $1.13(0.46-2.77)$ & 0.794 \\
\hline & Others ${ }^{\mathrm{a}}$ & $3.06(1.26-7.43)$ & $1.58(0.35-7.07)$ & 0.551 \\
\hline \multirow[t]{3}{*}{ Parity } & Primipara & 1 & 1 & \\
\hline & Multipara & $3.27(1.28-4.04)$ & $2.28(0.99-4.75)$ & 0.237 \\
\hline & Grand multipara & $3.69(1.50-9.06)$ & $2.20(0.68-7.15)$ & 0.189 \\
\hline \multirow[t]{2}{*}{ ANC visit } & Yes & 1 & 1 & \\
\hline & No & $1.72(0.93-3.16)$ & $0.41(0.12-1.45)$ & 0.166 \\
\hline \multirow[t]{2}{*}{ Iron supplementation } & Yes & 1 & 1 & \\
\hline & No & $1.67(0.95-2.93)$ & $1.13(0.34-3.81)$ & 0.839 \\
\hline \multirow[t]{2}{*}{ Hemoglobin } & $<11 \mathrm{~g} / \mathrm{dl}$ & $2.46(0.74-8.19)$ & $1.11(0.16-7.46)$ & 0.918 \\
\hline & $\geq 11 \mathrm{~g} / \mathrm{dl}$ & 1 & 1 & \\
\hline \multirow[t]{2}{*}{ Chronic hypertension } & Yes & $5.58(1.46-21.3)$ & $1.46(0.18-11.7)$ & 0.724 \\
\hline & No & 1 & 1 & \\
\hline \multirow[t]{2}{*}{ Pregnancy-induced hypertension } & Yes & $6.56(3.18-13.5)$ & $1.88(0.60-5.86)$ & 0.277 \\
\hline & No & 1 & 1 & \\
\hline \multirow[t]{2}{*}{ Danger signs during pregnancy } & Yes & $3.67(2.24-6.02)$ & $4.14(1.68-10.2)$ & 0.002 \\
\hline & No & 1 & 1 & \\
\hline \multirow[t]{2}{*}{ History of LBW } & Yes & $3.41(0.81-14.5)$ & $3.01(0.16-57.8)$ & 0.465 \\
\hline & No & 1 & 1 & \\
\hline \multirow[t]{4}{*}{ Maternal weight during pregnancy } & $50-60 \mathrm{~kg}$ & $5.08(1.97-13.0)$ & $4.94(3.26-7.52)$ & 0.000 \\
\hline & $61-70 \mathrm{~kg}$ & $2.95(1.16-7.46)$ & $6.42(2.46-9.13)$ & 0.001 \\
\hline & $71-80 \mathrm{~kg}$ & $1.32(0.49-3.50)$ & $2.57(0.65-10.3)$ & 0.181 \\
\hline & $\geq 81 \mathrm{~kg}$ & 1 & 1 & \\
\hline \multirow[t]{2}{*}{ Birth defect } & Yes & $3.08(0.86-11.1)$ & $3.18(0.38-26.4)$ & 0.283 \\
\hline & No & 1 & 1 & \\
\hline
\end{tabular}

Chi-square test was performed

LBW Low Birth Weight

${ }^{\text {a }}$ Daily laborer, waiter, tailor

timely report/seek medical care. In addition, regular antenatal care follow-up helps early detection and management of these disorders during pregnancy.

Moreover, maternal weight during pregnancy was found to be another determinant factor for low birth weight. Mothers whose pregnancy weight ranges from 50 to $60 \mathrm{~kg}$ were more likely to deliver low birth weight babies than those whose weight exceeds $81 \mathrm{~kg}$. This finding was consistent with a previous study in the context of five African countries: maternal underweight significantly increased the risk of low birth weight [3]. A similar result was also represented in China [9], India [19], Bale zone [15], and Jimma [21]. Anthropometric measurements are indicators of maternal nutritional status during pregnancy. In this case, maternal underweight shows chronic malnutrition, which impairs the growth and development of the fetus. Inadequate dietary intake during pregnancy has been shown to reduce the placental 
weight and surface area, limiting oxygen and nutrient transfer from the placenta to the fetus. Furthermore, poor maternal nutrition may decrease the serum concentrations of hormones, i.e., leptin and estrogen, which results in fetal growth impairment [11]. Therefore, it is recommended for pregnant women to have an adequate diet during pregnancy, particularly for its inter-generational effects [3].

Over $69 \%$ of women in the case group delivered before 37 completed weeks of gestation compared to only $3 \%$ in the control group. Similarly, in Brazil, prematurity increased the odds of LBW ten times [24]. In addition, a study in Amhara region referral hospitals found a significantly low birth weight among preterm deliveries [23]. This could be because many of the baby's organs and basic body systems are not fully matured. The earlier the baby was born, the higher the risk of low birth weight.

\section{Limitation of the study}

Since secondary data were used, some potential risk factors such as income, height, mid-upper arm circumference, alcohol use, and smoking status could not be obtained.

\section{Conclusion}

Residence, occupation, danger signs, and maternal weight during pregnancy were significant determinants of low birth weight. Socioeconomic development, early detection and management of complications, and encouraging nutrition and weight during pregnancy are crucial to minimizing the risk of delivering low birth weight babies. The health care providers would be better to emphasize antenatal counseling and health promotion regarding nutrition and danger signs with the appropriate actions to be taken.

\footnotetext{
Abbreviations

ANC: Antenatal care; AOR: Adjusted odds ratio; Cl: Confidence interval; COR: Crude odds ratio; EDHS: Ethiopian Demographic and Health Survey; LBW: Low birth weight; NBW: Normal birth weight; SPSS: Statistical Package for Social Science; WHO: World Health Organization.
}

\section{Acknowledgments}

First, we would like to extend our deepest gratitude to Tirunesh Beijing General Hospital for permitting us to conduct the study. We would also like to extend our appreciation to the data collectors and supervisors.

\section{Authors' contributions}

MT and AS conceived the study, performed the analysis, interpreted, and drafted the manuscript. CT, FK, and GB contributed to the interpretation of data and critically revised the manuscript. All authors read and approved the final manuscript.

\section{Funding}

None.

\section{Availability of data and materials}

Data supporting these findings are contained within the manuscript and shared upon request to the corresponding author.

\section{Declarations}

Ethics approval and consent to participate

An ethical clearance letter was obtained from Debre Berhan University Research Ethics and Publication Committee. Additional permission was gained from the Tirunesh Beijing General Hospital administration to utilize the birth records. Since we used secondary data from maternal antenatal care files and birth records, informed consent is not applicable for study participants. Informed consent was waived by the Debre Berhan University Research Ethics and Publication Committee. Any information related to the study participants' identification was not recorded to maintain the confidentiality of the study. All methods were performed following the declaration of Helsinki ethical principles.

\section{Consent for publication \\ Not applicable.}

\section{Competing interests}

The authors declare that they have no conflict of interest.

\section{Author details}

'Department of Midwifery, College of Health Sciences, Debre Berhan University, Debre Berhan, Ethiopia. ${ }^{2}$ Department of Nursing, College of Health Sciences, Debre Berhan University, Debre Berhan, Ethiopia.

Received: 12 April 2021 Accepted: 15 November 2021

Published online: 27 November 2021

\section{References}

1. Demographic IE. Health survey 2016: key indicators report. Addis Ababa, Rockville: Ethiopia Demographic and Health Survey; 2016.

2. WHO. Global nutrition targets 2025: low birth weight policy brief. Glob Nutr Targets. 2014;2015:2025.

3. He Z, Bishwajit G, Yaya S, Cheng Z, Zou D, Zhou Y. Prevalence of low birth weight and its association with maternal body weight status in selected countries in Africa: a cross-sectional study. BMJ Open. 2018:8(8):e020410.

4. Tessema ZT, Tamirat KS, Teshale AB, Tesema GA. Prevalence of low birth weight and its associated factor at birth in Sub-Saharan Africa: a generalized linear mixed model. PLoS One. 2021;16(3):e0248417.

5. Toru T, Anmut W. Assessment of low birth weight and associated factors among neonates in Butajira General Hospital, South Ethiopia, cross sectional study, 2019. Int J Pediatr. 2020;2020:5841963.

6. Lake EA, Olana Fite R. Low birth weight and its associated factors among newborns delivered at wolaita sodo university teaching and referral hospital, southern Ethiopia, 2018. Int J Pediatr. 2019;2019:4628301.

7. Briggs ND. Life depends on birthweight-the second john bateman lawson memorial oration. Trop J Obstet Gynaecol. 2004;21(1):71-7.

8. Kaur S, Ng CM, Badon SE, Jalil RA, Maykanathan D, Yim HS, et al. Risk factors for low birth weight among rural and urban Malaysian women. BMC Public Health. 2019;19(4):1-10.

9. Xi C, Luo M, Wang T, Wang Y, Wang S, Guo L, et al. Association between maternal lifestyle factors and low birth weight in preterm and term births: a case-control study. Reprod Health. 2020;17(1):1-9.

10. Demographic E. Health survey 2011 central statistical agency Addis Ababa. Calverton: ICF International; 2012. p. 70-1.

11. Endalamaw A, Engeda EH, Ekubagewargies DT, Belay GM, Tefera MA. Low birth weight and its associated factors in Ethiopia: a systematic review and meta-analysis. Ital J Pediatr. 2018:44(1):1-12.

12. WHO. The state of child health in the Eastern Mediterranean region. 1995.

13. Adane AA, Ayele TA, Ararsa LG, Bitew BD, Zeleke BM. Adverse birth outcomes among deliveries at Gondar University hospital, Northwest Ethiopia. BMC Pregnancy Childbirth. 2014;14(1):1-8. 
14. Hailu LD, Kebede DL. Determinants of low birth weight among deliveries at a referral Hospital in Northern Ethiopia. Biomed Res Int. 2018;2018(Article ID 8169615):8. https://doi.org/10.1155/2018/8169615.

15. Demelash H, Motbainor A, Nigatu D, Gashaw K, Melese A. Risk factors for low birth weight in Bale zone hospitals, South-East Ethiopia: a case-control study. BMC Pregnancy Childbirth. 2015;15(1):1-10.

16. Zenebe K, Awoke T, Birhan N. Low birth weight \& associated factors among newborns in Gondar town, North West Ethiopia: institutional based cross-sectional study. Indo Glob J Pharm Sci. 2014:4(2):74-80.

17. Mehare T, Sharew Y. Prevalence and associated factors of low birth weight among term newborns in Dilla Town, Southern Ethiopia. Int J Pediatr. 2020;2020(Article ID 8394578):7. https://doi.org/10.1155/2020/8394578.

18. EDHS E. Demographic and health survey 2016: key indicators report. The DHS Program ICF. 2016;363:364.

19. Nagargoje MM, Chaudhary SS, Deshmukh JS, Gupta SC, Misra SK. A case control study of risk factors for low birth weight in Nagpur city of Maharashtra. Indian J Community Health. 2011;23(1):4-7.

20. Mahmoodi Z, Karimlou M, Sajjadi H, Dejman M, Vameghi M, Dolatian M. Working conditions, socioeconomic factors and low birth weight: path analysis. Iran Red Crescent Med J. 2013;15(9):836

21. Tema T. Prevalence and determinants of low birth weight in Jimma Zone, Southwest Ethiopia. East Afr Med J. 2006;83(7):366.

22. Snijder CA, Brand T, Jaddoe V, Hofman A, Mackenbach JP, Steegers EAP, et al. Physically demanding work, fetal growth and the risk of adverse birth outcomes. The Generation R Study. Occup Environ Med. 2012;69(8):543-50.

23. Asmare G, Berhan N, Berhanu M, Alebel A. Determinants of low birth weight among neonates born in Amhara Regional State Referral Hospitals of Ethiopia: unmatched case control study. BMC Res Notes. 2018;11(1):1-7.

24. Belfort GP, Santos MMADS, Pessoa LDS, Dias JR, Heidelmann SP, Saunders C. Determinants of low birth weight in the children of adolescent mothers: a hierarchical analysis. Cien Saude Colet. 2018;23:2609-20.

\section{Publisher's Note}

Springer Nature remains neutral with regard to jurisdictional claims in published maps and institutional affiliations.

Ready to submit your research? Choose BMC and benefit from:

- fast, convenient online submission

- thorough peer review by experienced researchers in your field

- rapid publication on acceptance

- support for research data, including large and complex data types

- gold Open Access which fosters wider collaboration and increased citations

- maximum visibility for your research: over $100 \mathrm{M}$ website views per year

At BMC, research is always in progress.

Learn more biomedcentral.com/submissions 